\title{
Investigating the Possibility to Individualize Asthma Attack Therapy Based on Attack Severity and Patient Characteristics
}

\author{
Sárkány $Z^{1^{*}}$, Sárkány Kinga², Horváth $A^{3}$ \\ 1 University of Medicine and Pharmacy, TârguMureș, Romania \\ ${ }^{2}$ County Emergency Clinical Hospital, TârguMureș, Romania \\ ${ }^{3}$ Chiesi Pharmaceuticals, Budapest, Hungary
}

\begin{abstract}
Introduction: The objective of this study was to investigate with the help of a computerized simulation model whether the treatment of an acute asthma attack can be individualized based on the severity of the attack and the characteristics of the patient. Material and Method: A stochastic lung model was used to simulate the deposition of $1 \mathrm{~nm}-10 \mu \mathrm{m}$ particles during a mild and a moderate asthma attack. Breathing parameters were varied to maximize deposition, and simulation results were compared with those obtained in the case of a severe asthma attack. In order to investigate the effect of height on the deposition of inhaled particles, another series of simulations was carried out with identical breathing parameters, comparing patient heights of $155 \mathrm{~cm}, 175 \mathrm{~cm}$ and $195 \mathrm{~cm}$. Results: The optimization process yielded an increase in the maximum deposition values of around 6-7\% for each type of investigated asthma attack, and the difference between attacks of different degree of severity was around $5 \%$ for both the initial and the optimized values, a higher degree of obstruction increasing the amount of deposited particles. Conclusions: Our results suggest that the individualization of asthma attack treatment cannot be based on particles of different size, as the highest deposited fraction in all three types of attacks can be obtained using $0.01 \mu \mathrm{m}$ particles. The use of a specific set of breathing parameters yields a difference between a mild and a moderate, as well as a moderate and a severe asthma attack of around $5 \%$.
\end{abstract}

Keywords: asthma, modeling, stochastic, inhalation, particles

Received: 11 September 2015 / Accepted: 02 November 2015

\section{Introduction}

As we edge closer to the era of personalized medicine, the concept of individualized treatment brings hope for patients diagnosed with diseases where treatment efficiency has been less than satisfactory with the current methods of treatment. One of these diseases is asthma bronchiale, where the efficiency of inhalation treatment is relatively low [1], and approximately one third of the patients do not respond at all to corticosteroid treatment [2]. This can be attributed probably to the large number of factors that can influence the efficiency of treatment, from the characteristics of the inhaled aerosol, to patient related factors like age, stage of pulmonary disease, individual breathing pattern or the morphometry of the lower airways [3], as well as to the individual variations in response to treatment [4].

Given the multitude of factors influencing the treatment of asthma, individualized treatment certainly seems the next logical step in its management. It has been shown that individualized self-management programs contribute to the amelioration of symptoms and reduce the frequency of attacks [5], but most personalized treatment plans refer to individually adjusted types of medication and dosages. Recent studies approach asthma therapy individualization from a genetic [6-8], immunologic [9] or biologic [10-12] point of view.

* Correspondence to: Zoltán Sárkány

E-mail: sarkanyzoltan@gmail.com
Our study would like to take a different approach to the concept of asthma therapy individualization, starting with the inhaled medication and the inhalation technique. The objective of this study was to investigate with the help of a computerized simulation model whether the treatment of an acute asthma attack can be individualized based on the severity of the attack and the characteristics of the patient.

\section{Material and methods}

The simulations were carried out using the stochastic lung model, presented in detail in previous papers $[13,14]$. We modelled the inhalation of $1 \mathrm{~nm}-10 \mu \mathrm{m}$ particles by an adult male during a $10 \mathrm{~s}$ symmetrical breathing cycle with a $2000 \mathrm{ml}$ tidal volume, and calculated the total amount of particles deposited in bronchial generations 9-16, using parameters characteristic of a mild (functional residual capacity $3500 \mathrm{ml}$, probability of obstruction $75 \%$, degree of obstruction 5-20\%) and a moderate (functional residual capacity $4000 \mathrm{ml}$, probability of obstruction $90 \%$, degree of obstruction 20-40\%) asthma attack respectively.

The present work is the continuation of a previous study regarding the maximization of the amount of deposited therapeutic particles in bronchial generations 9-16, inhaled during a severe asthma attack [14]. That study has shown that the highest deposition values in this area can be obtained with $0.01 \mu \mathrm{m}$ particles, inhaled during an $8 \mathrm{~s}$ symmetrical breathing cycle with a $1 \mathrm{~s}$ breath-hold, using a $3000 \mathrm{ml}$ tidal volume. The current study used a similar 
concept regarding the simulations: once we found the particle size that yielded the highest amount of deposited particles in the investigated region, we used that particle size as a starting point for a new series of simulations, aimed to maximize the deposited fraction of the inhaled particles, changing one parameter at a time, in a well-defined interval: the tidal volume between $750-3000 \mathrm{ml}$, the length of the breathing cycle between 2-20 seconds and the length of the breath-hold following inhalation between 0-10 s. The initial and optimized total deposition values in bronchial generations 9-16 obtained in the case of a mild and a moderate asthma attack respectively were then compared with those obtained in the previous study in the case of a severe asthma attack.

To quantify the effect of inter-subject variations - expressed through variations in the height, and subsequently in the FRC values of patients - have on the deposition of inhaled particles, and to investigate whether the treatment of an asthma attack can be individualized based on the variations of these parameters, another series of simulations was carried out for patients with different heights and corresponding FRC values in case of a severe asthma attack. The simulated patient heights were $155 \mathrm{~cm}, 175 \mathrm{~cm}$ and
$195 \mathrm{~cm}$, and the corresponding FRC values were $2887 \mathrm{ml}$, $3355 \mathrm{ml}$ and $3823 \mathrm{ml}$ respectively. These FRC values were calculated based on the formula of Stocks and Quanjer[15]:

FRC $(\mathrm{l})=2.34 \times$ height $(\mathrm{m})+0.01 \times$ age $(\mathrm{yrs})-1.09$

All simulations were carried out for one complete breathing cycle, assuming the inhalation of monodisperse particles through oral breathing and that the particles are inhaled uniformly during inhalation. Data processing and statistical analysis were carried out with Microsoft Excel 2010, using Student's t test to compare the results, and a $\mathrm{p}$ level below 0.05 was considered to be statistically significant.

\section{Results}

In the first series of simulations we modelled the deposition of $1 \mathrm{~nm}-10 \mu \mathrm{m}$ particles in bronchial generations 9-16 in the case of a mild asthma attack. Deposition fractions in the investigated area are presented in panels A, B, $\mathrm{C}$ and $\mathrm{D}$ of Figure 1.

The highest total deposited fraction of $41.80 \%$ in bronchial generations 9-16 was obtained in the case of $0.01 \mu \mathrm{m}$
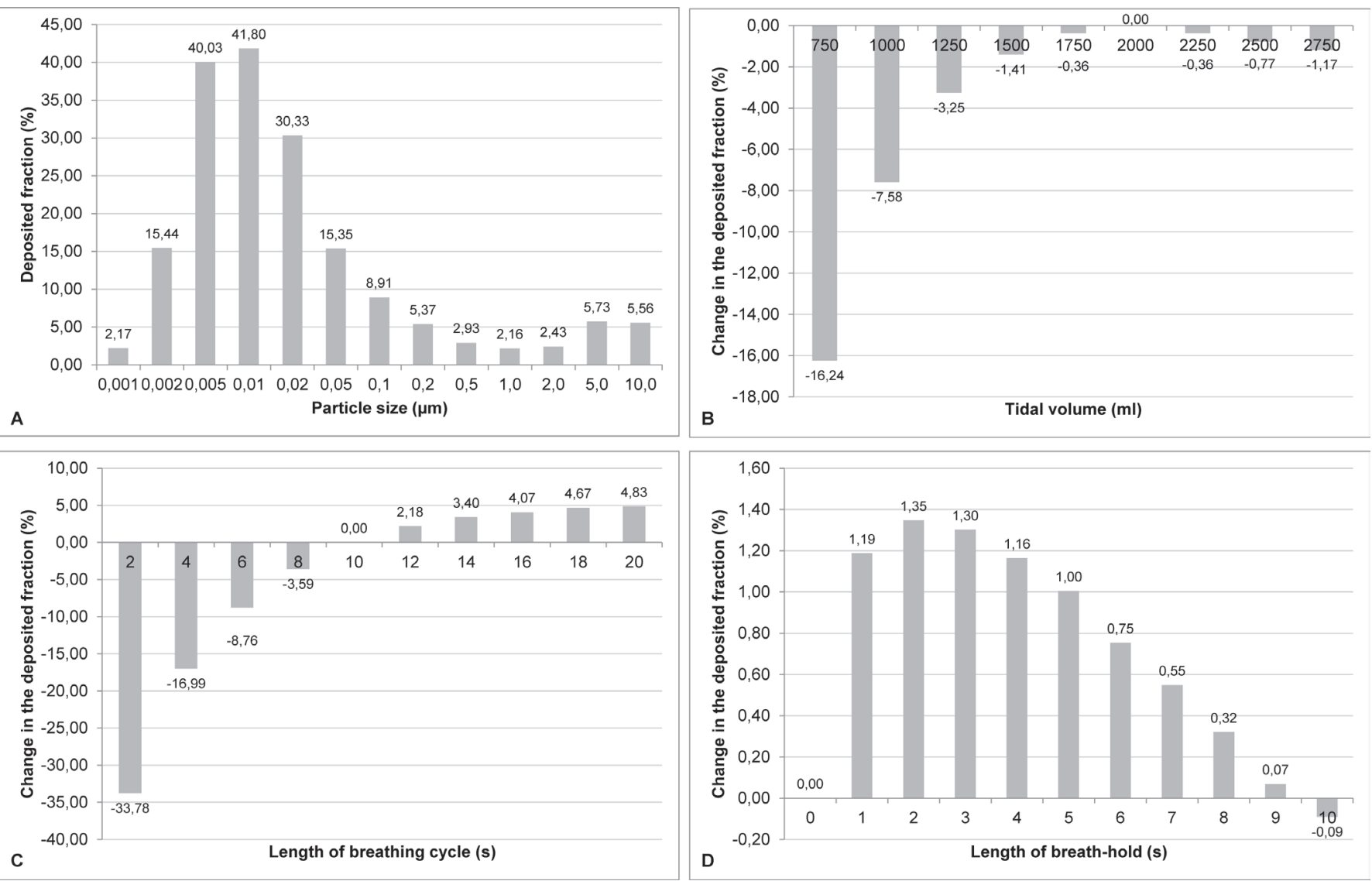

Fig. 1. A. Total deposition values of $1 \mathrm{~nm}-10 \mu \mathrm{m}$ particles in generations 9-16 during a mild asthma attack $\left(\mathrm{FRC}=3500 \mathrm{ml}, \mathrm{V}_{\mathrm{T}}=2000\right.$ $\left.\mathrm{ml}, \mathrm{T}_{\text {inh }}=5 \mathrm{~s}, \mathrm{~T}_{\text {exh }}=5 \mathrm{~s}, \mathrm{~T}_{\mathrm{bh}}=0 \mathrm{~s}\right) . \mathrm{p}<0.001$ for all comparisons. B. Percentual change in the deposition fractions of $0.01 \mu \mathrm{m}$ particles in generations 9-16 during a mild asthma attack, with tidal volumes ranging between $750-3000 \mathrm{ml}\left(\mathrm{FRC}=3500 \mathrm{ml}, \mathrm{T}_{\text {inh }}=5 \mathrm{~s}, \mathrm{~T}_{\text {exh }}=5 \mathrm{~s}\right) . \mathrm{p}$ $<0.001$ for all comparisons. C. Percentual change in the deposition fractions of $0.01 \mu \mathrm{m}$ particles in generations $9-16$ during a severe asthma attack, with symmetrical breathing cycles ranging between $2-20 \mathrm{~s}\left(\mathrm{FRC}=3500 \mathrm{ml}, \mathrm{V}_{\mathrm{T}}=2000 \mathrm{ml}\right)$. $\mathrm{p}<0.001$ for all comparisons. D. Percentual change in the deposition fractions of $0.01 \mu \mathrm{m}$ particles in generations 9-16 during a severe asthma attack, with a breathhold following inhalation ranging between $0-10 \mathrm{~s}\left(\mathrm{FRC}=3500 \mathrm{ml}, \mathrm{V}_{\mathrm{T}}=2000 \mathrm{ml}, \mathrm{T}_{\text {inh }}=10 \mathrm{~s}, \mathrm{~T}_{\text {exh }}=10 \mathrm{~s}\right) . \mathrm{p}<0.001$ for all comparisons. 
particles (Figure 1A), and the simulations were continued using this particle size, changing the other parameters one at a time. The effect of varying the tidal volume between 750 and $3000 \mathrm{ml}$ is shown in Figure 1B. The results show that varying the tidal volume in the specified interval did not increase the deposited fraction, therefore the simulations were continued with a tidal volume of $2000 \mathrm{ml}$. Varying the length of the breathing cycle yielded an increase of $4.83 \%(43.82 \%$ vs. $41.80 \%)$ in the case of a 20 s symmetrical breathing cycle (Figure 1C), and varying the length of breath-hold following inhalation led to an increase of $1.35 \%(44.41 \%$ vs. $43.82 \%)$ in the case of a breath-hold of 2 seconds (Figure 1D). Therefore, following optimization, the total deposited fraction in bronchial generations 9-16 in the case of a mild asthma attack was $44.41 \%$ (a $6.24 \%$ increase over the initial value of $41.80 \%$ ).

In the second series of simulations we modelled the deposition of inhaled particles in bronchial generations 9-16 during a moderate asthma attack. Deposition values for the wide range of investigated particles are presented in panels A, B, C and D of Figure 2.

In the case of a moderate attack, the highest deposited fraction of $46.21 \%$ was obtained using $0.01 \mu \mathrm{m}$ parti- cles (Figure 2A). Continuing the simulations with this particle size, varying the tidal volumes yielded a maximum increase of $0.39 \%$ ( $46.39 \%$ vs. $46.21 \%$ ) in the case of a tidal volume of $2750 \mathrm{ml}$ (Figure 2B), varying the length of the breathing cycle yielded a further increase of $4.7 \%$ (48.57\% vs. $46.39 \%)$ when using a 20 s symmetrical breathing cycle (Figure $2 \mathrm{C}$ ), and varying the length of breath-hold following inhalation yielded an increase of $0.95 \%(49.03 \%$ vs. $48.57 \%)$ in the case of a breathhold of 2 seconds (Figure 2D). In conclusion, following optimization, the total deposited fraction in bronchial generations $9-16$ in the case of a moderate asthma attack was $49.03 \%$ (a $6.1 \%$ increase over the initial value of $46.21 \%$.

Figure 3 presents a comparison between the initial and the optimized total deposition values in bronchial generations 9-16, obtained in the case of a mild, a moderate and a severe asthma attack, while the optimized parameters that lead to the highest deposited fractions in the target areas are presented in Table I.

The results show that the quantity of deposited particles increases with the severity of the asthma attack, the difference between the mild and the severe attack amounting to
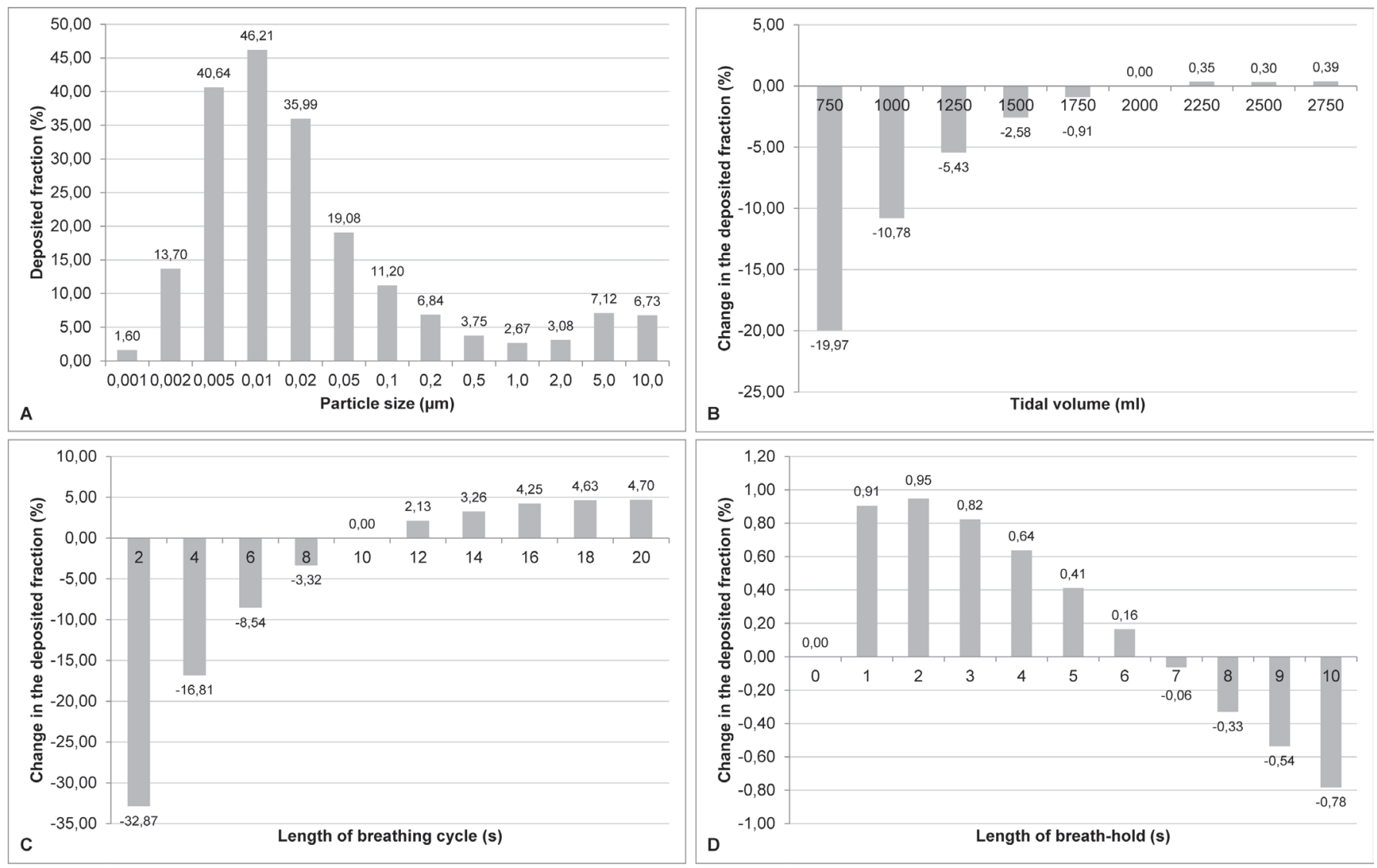

Fig. 2. A. Total deposition values of $1 \mathrm{~nm}-10 \mu \mathrm{m}$ particles in generations 9-16 during a moderate asthma attack $\left(\mathrm{FRC}=4000 \mathrm{ml}, \mathrm{V}_{\mathrm{T}}=\right.$ $2000 \mathrm{ml}, \mathrm{T}_{\mathrm{inh}}=5 \mathrm{~s}, \mathrm{~T}_{\mathrm{exh}}=5 \mathrm{~s}, \mathrm{~T}_{\mathrm{bh}}=0 \mathrm{~s}$ ). $\mathrm{p}<0.001$ for all comparisons. B. Percentual change in the deposition fractions of $0.01 \mu \mathrm{m}$ particles in generations 9-16 during a mild asthma attack, with tidal volumes ranging between $750-3000 \mathrm{ml}\left(\mathrm{FRC}=4000 \mathrm{ml}, \mathrm{T}_{\text {inh }}=5 \mathrm{~s}, \mathrm{~T}_{\text {exh }}=5 \mathrm{~s}\right)$. $p<0.001$ for all comparisons. C. Percentual change in the deposition fractions of $0.01 \mu \mathrm{m}$ particles in generations $9-16$ during a severe asthma attack, with symmetrical breathing cycles ranging between $2-20 \mathrm{~s}\left(\mathrm{FRC}=4000 \mathrm{ml}, \mathrm{V}_{\mathrm{T}}=2750 \mathrm{ml}\right)$. $\mathrm{p}<0.001$ for all comparisons. D. Percentual change in the deposition fractions of $0.01 \mu \mathrm{m}$ particles in generations 9-16 during a severe asthma attack, with a breathhold following inhalation ranging between 0-10 s $\left(F R C=4000 \mathrm{ml}, V_{T}=2750 \mathrm{ml}, \mathrm{T}_{\text {inh }}=10 \mathrm{~s}, \mathrm{~T}_{\text {exh }}=10 \mathrm{~s}\right) . \mathrm{p}<0.001$ for all comparisons. 
around $10 \%$ for both the initial $(51.5 \%$ vs. $41.8 \%)$ and the optimized ( $55.32 \%$ vs. $44.41 \%)$ deposition values.

As far as inter-subject variability is concerned, the results of the simulations carried out with different patient heights are shown in Figure 4.

The results show that in case of identical breathing parameters a larger patient height - and consequently a larger functional residual capacity - increases the amount of deposited particles, but while the height difference between two investigated categories is $20 \mathrm{~cm}$, the difference between the deposition fractions is only $1-2 \%$.

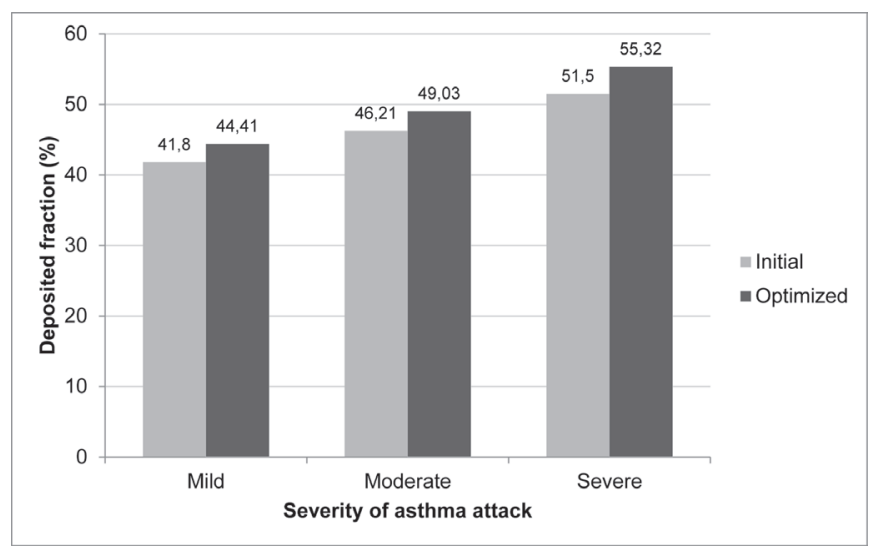

Fig. 3. Comparison between the initial and the optimized total deposition values in bronchial generations 9-16 obtained in the case of a mild, a moderate and a severe asthma attack. $p<0.001$ for all comparisons.

Table I. The optimized parameters that lead to the highest deposited fractions in the target areas

\begin{tabular}{lccc}
\hline & $\begin{array}{c}\text { Mild asthma } \\
\text { attack }\end{array}$ & $\begin{array}{c}\text { Moderate } \\
\text { asthma attack }\end{array}$ & $\begin{array}{c}\text { Severe } \\
\text { asthma attack }\end{array}$ \\
\hline Particle size & $0.01 \mu \mathrm{m}$ & $0.01 \mu \mathrm{m}$ & $0.01 \mu \mathrm{m}$ \\
Tidal volume & $2000 \mathrm{ml}$ & $2750 \mathrm{ml}$ & $3000 \mathrm{ml}$ \\
Length of breathing cycle & $20 \mathrm{~s}$ & $20 \mathrm{~s}$ & $8 \mathrm{~s}$ \\
Length of breath-hold & $2 \mathrm{~s}$ & $2 \mathrm{~s}$ & $1 \mathrm{~s}$ \\
following inhalation & & &
\end{tabular}

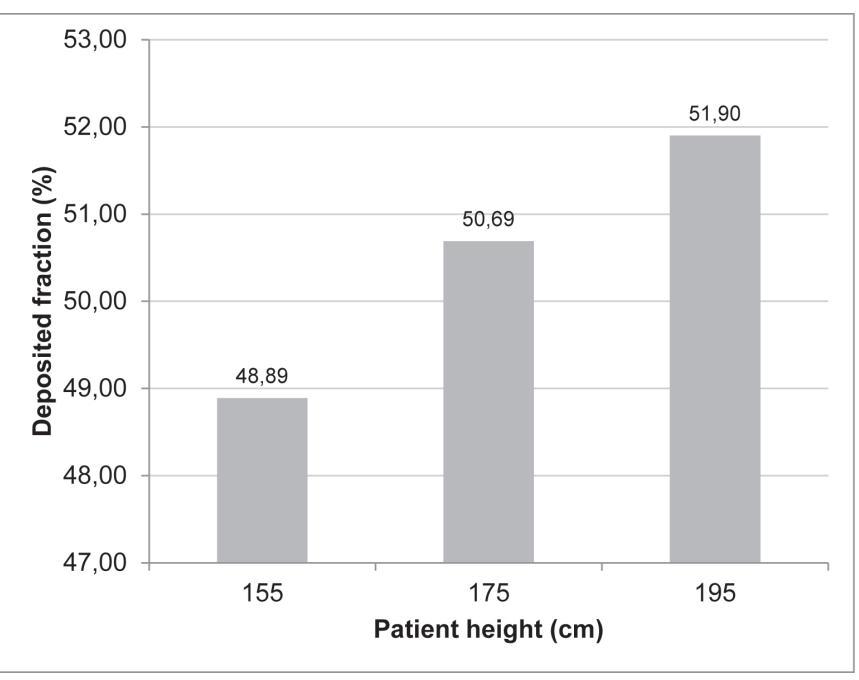

Fig. 4. Comparison between the deposition values of $0.01 \mu \mathrm{m}$ particles in bronchial generations 9-16 corresponding to different patient heights during a severe asthma attack $\left(\mathrm{V}_{\mathrm{T}}=3000 \mathrm{ml}, \mathrm{T}_{\mathrm{inh}}=\right.$ $\left.4 \mathrm{~s}, \mathrm{~T}_{\text {exh }}=4 \mathrm{~s}, \mathrm{BP}=1 \mathrm{~s}\right) . \mathrm{p}<0.001$ for all comparisons.

\section{Discussion}

Our previous study regarding the maximization of the amount of deposited therapeutic particles inhaled during a severe asthma attack in bronchial generations 9-16 has shown that the highest deposition values in this area can be obtained with $0.01 \mu \mathrm{m}$ particles, inhaled during an 8 $s$ breathing cycle with a $1 \mathrm{~s}$ breath-hold following inhalation, using a $3000 \mathrm{ml}$ tidal volume [14]. The idea behind the current study was to investigate whether the differences in the deposition efficiencies of therapeutic particles inhaled during a mild, a moderate and a severe asthma attack are large enough to warrant the use of particles with different diameters and/or different breathing patterns in each of these situations. Another question was should we use particles with different diameters and/or different breathing patterns in case of patients with large differences in their height, but the same degree of asthma attack severity?

As far as particle size is concerned, our results show that in all three cases the highest quantity of deposited particles can be obtained with $0.01 \mu \mathrm{m}$ particles, suggesting that particle size is not a factor that the individualization of asthma attack therapy should be based on. Thus, the differences observed in the deposition efficiency of particles inhaled during the modelled attacks are due to a mixture of breathing- and patient-related parameters that contribute differently to the process of particle deposition. One of these parameters is the obstruction of the airways, which seems to be the main factor behind the differences observed when comparing attacks of different severities. A higher degree of obstruction increases the deposition of the inhaled particles as shown in other studies [16-18], but the difference between the mild and the severe asthma attack is around $10 \%$ in case of identical breathing parameters. Using an optimized set of breathing parameters increases maximum deposition values by $6-7 \%$, but essentially this $10 \%$ difference - around 5\% between the mild and the moderate attack, and 5\% between the moderate and the severe attack - is maintained even after optimization. The relatively small increase in the deposited fraction that could be obtained with the change of breathing parameters may be due to the fact that the deposition of particles of this size is less sensitive to the variations of breathing parameters, as shown in a previous study [14]. Further studies are needed to assess whether these differences are large enough to warrant the use of a specific set of breathing parameters during an attack. The effect of height on particle deposition is less pronounced, as an increase of $20 \mathrm{~cm}$ in the patient's height increases the deposited fraction between 1-2\%.

One of the study's limitations is the fact that intersubject variability was assessed only through the patients' height, and other patient-related parameters, such as age, were not taken into consideration. Also, there are other parameters, such as the Body Mass Index, which may be better suited to investigate the effect of patient-related parameters on the efficiency of particle deposition [19]. The investigation of such parameters is currently not possible 
with the stochastic lung model, but may be implemented in the future. It should also be noted that even if in a modelling environment the use of ideal parameters yields statistically significant differences between the maximum deposited fractions that can be obtained during asthma attacks of different severity, in vivo the efficiency of particle deposition is influenced by a large number of factors, and ultimately the decision whether a particular patient can benefit from the use of a particular breathing pattern has to be made by the physician.

\section{Conclusion}

The results of this study suggest that the individualization of asthma attack therapy cannot be based on using particles of different size in the case of attacks with different degrees of severity, as the largest amount of therapeutic particles deposited in bronchial generations 9-16 during a mild, a moderate and a severe asthma attack can be obtained using particles with a diameter of $0.01 \mu \mathrm{m}$. Maximizing the amount of deposited particles using a specific set of breathing parameters results in a difference of around $5 \%$ between a mild and a moderate, as well as a moderate and a severe asthma attack. While this difference is significant statistically, its benefit remains to be assessed through further studies.

\section{Acknowledgement}

This paper is supported by the Sectoral Operational Programme Human Resources Development (SOP HRD), financed from the European Social Fund and by the Romanian Government under the contract number POSDRU/159/1.5/S/133377.

\section{References}

1. Usmani OS, Biddiscombe MF, Nightingale JA, Underwood SR, Barnes PJ. Effects of bronchodilator particle size in asthmatic patients using monodisperse aerosols. J Appl Physiol. 2003;95:2106-2112.
2. Szefler SJ, Phillips BR, Martinez FD, et al. Characterization of withinsubject responses to fluticasone and montelukast in childhood asthma. J Allergy Clinlmmunol. 2005;115:233-242.

3. Fischer A, Stegemann J, Scheuch G, Siekmeier R. Novel devices for individualized controlled inhalation can optimize aerosol therapy in efficacy, patient care and power of clinical trials. Eur J Med Res. 2009;14(Suppl. IV):71-77.

4. Haughney J, Price D, Kaplan A, et al. Achieving asthma control in practice: understanding the reasons for poor control. Respir Med. 2008;102:1681-93.

5. Kotses H, Stout C, McConnaughy K, Winder JA, Creer TL. Evaluation of individualized asthma self-management programs. J Asthma. 1996;33(2):113-8.

6. Fingleton J, Beasley R. Individualized treatment for asthma. Advances in Asthma Management. 2012;156-166.

7. Tantisira KG et al. Genomewide Association between GLCCl1 and Response to Glucocorticoid Therapy in Asthma. N Engl J Med. 2011;365:1173-1183.

8. Portelli M, Sayers I. Genetic basis for personalized medicine in asthma. Expert Rev Respir Med. 2012;6(2):223-36.doi:10.1586/ers.12.9.

9. Poon $\mathrm{AH}$, Hamid Q. Asthma Endotypes: The Right Direction Towards Personalized Medicine for Asthma. Expert Rev Clin Immunol. 2012;8(7):595-596.

10. Fajt ML, Wenzel SE. Biologic therapy in asthma: entering the new age of personalized medicine. J Asthma. 2014;51(7):669-76.

11. Fajt ML, Wenzel SE. Asthma phenotypes and the use of biologic medications in asthma and allergic disease: the next steps toward personalized care. J Allergy Clin Immunol. 2015;135(2):299-310.

12. Darveaux J, Busse WW. Biologics in Asthma - The Next Step Toward Personalized Treatment. The Journal of Allergy and Clinical Immunology: In Practice. 2015;3(2):152-160.

13. Sárkány Z, Horváth A, Balásházy I, Hofmann W, Brînzaniuc K, Sabău M. Evaluation of inhaled drug deposition during an asthma attack using a stochastic lung model. Acta Medica Transilvanica. 2013;2(1):238-240.

14. Sárkány Z. Maximizing the amount of deposited particles during a severe asthma attack using the stochastic lung model. Acta Medica Marisiensis 2015;61(3):157-160.doi:10.1515/amma-2015-0043.

15. Stocks J, Quanjer $\mathrm{PhH}$. Reference values for residual volume, functional residual capacity and total lung capacity. Eur Respir J. 1995;8:492-506.

16. Martonen TB, Fleming J, Schroeter J, Conway J, Hwang D. In silico modelling of asthma. Advanced. Drug Delivery Reviews. 2003;55:829849.

17. Chalupa DC, Morrow PE, Oberdorster G, Utell MJ, Frampton MW. Ultrafine particle deposition in subjects with asthma. Environmental Health Perspectives. 2004;112:879-882.

18. Longest PW, Vinchurkar S, Martonen T. Transport and deposition of respiratory aerosols in models of childhood asthma. Journal of Aerosol Science. 2006;37:1234-1257.

19. Jones RL, Nzekwu MM. The effects of body mass index on lung volumes. Chest. 2006 Sep;130(3):827-33. 